\title{
Digital images of medieval music documents: transforming research processes and knowledge production in musicology
}

\author{
Grace Eden \\ University of Oxford \\ Oxford e-Research Centre \\ Oxford, UK \\ grace.eden@oerc.ox.ac.uk
}

\author{
Marina Jirotka \\ University of Oxford \\ Oxford e-Research Centre \\ Oxford, UK \\ marina.jirotka@oerc.ox.ac.uk
}

\begin{abstract}
Musicologists who study medieval music manuscripts were up until recently required to travel to the libraries and museums where these documents or their fragments are physically held. Increasingly however, digital image archives provide resources that allow scholars to conduct much of their research through both the inspection and manipulation of digital images. These images effectively serve as proxies for each physical document they display, and their use as research objects in their own right is bringing about transformative effects for the way research in medieval musicology is conducted. We discuss the results of a qualitative workplace study conducted to understand the transformative effects of digital images on research practice and to identify emerging requirements that might inform the design of more novel digital image archive systems. We show how qualitative fieldwork provides insight into how researchers actually use systems in order to inform incremental improvements to prototypes and novel designs.
\end{abstract}

\section{Introduction}

Technological developments in e-Science and Cyberinfrastructure are aimed at supporting scientists, engineers and scholars across a wide range of academic disciplines so that they may collaborate with partners who are both collocated and geographically distributed. Designed specifically to support research, these systems assist scholars in their research practice as well as to enable communication and collaboration with remote colleagues so that they may share expertise and participate in large-scale multiinstitutional distributed projects. These advanced technological innovations have heralded a potential revolution in the way research is undertaken globally $[1,12]$.

For e-Research projects to succeed, they require the expertise of multi-disciplinary teams. This includes technical experts and engineers working together with researchers in the sciences, engineering, the social sciences and humanities in the design of complex computing infrastructures and software applications that support the research goals of those who would use the system. Additionally, there is work to be done in the assessment and evaluation of new technologies as they become embedded into research contexts. Such assessments can assist us in understanding how new technologies may or may not transform scientific research as well as to identify requirements that emerge as scholars use them to support real-world research.

We take this programme of work as our starting point in our investigations into how e-Research technologies are transforming research practices in the humanities [8] and the physical sciences [9] and find common themes emerging around both increased collaboration and speed of research outputs. Here, we discuss a particular area in the humanities - medieval musicology where research practices are in transition due to the increasing digitization and availability of the documents, written on parchment and paper, music was written on at that time.

\section{Medieval musicology}

Medieval musicology is the study of music composed and performed from the 5th century to the 15th century (approx. 400-1400). These music manuscripts are handwritten documents produced by scribes with very few surviving in their complete form and with most being damaged and fragmentary. In many cases fragments have been preserved only because they were re-used as book binding material or for other purposes such as chair stuffing, papering for ceilings, hat-box linings and padding for musical instrument cases [6].

Medieval musicologists are interested in these source manuscripts for a variety of reasons. Scholars study their content to understand both secular and 
sacred music within a specific time period and draw out its relationship to historical events. For instance, scholars attempt to reconstruct fragmentary pieces with reference to other manuscripts as well as compare compositional styles and notational variation. They may conduct analyses of song in courtly contexts to understand how they were used to communicate political ideas as well as create coherence within a community. In addition, the layout and typography of manuscripts is of great interest for understanding how to read, interpret and actually perform these musical works today.

Traditionally, medieval musicologists conduct their research through the analysis of actual manuscript documents (Fig. 1). Traditional tools include the use of a magnifying glass to inspect the content within documents, rulers to measure its size and physical handling to analyse characteristics such as leaf texture, parchment weight, book binding, pigments used, and to assess its overall condition. Medieval musicologists are also interested in understanding the sounds that a series of musical notes might represent. Additionally, they may reference other kinds of material associated with a manuscript such as facsimile books (high-quality photographs) or microfiche (black and white or colour negatives approx. 25 times smaller than the original document's size accessed through a reading machine and then magnified).

Through these activities medieval musicologists inspect both the condition and content of medieval documents in order to make sense of its physical properties such as parchment weight, folio size, colour and its subject matter through interpreting transcriptions of how musical notes are organised into rhythmic and melodic sections as well as identifying the writing styles of different scribes. Recently, manuscripts have been digitized and placed into online archives initially to preserve rare and fragile materials, however, increasingly they have become a source of scholarly interest. Our case study discusses how access to high resolution digital images supports scholarly research and offers insight into the ways in which new technologies are transforming research practices in order to identify emerging requirements. This includes the ways in which they examine digital images of physical documents to compare different compositional styles as well as digital restoration processes that may uncover musical notes that are not visible otherwise.

We conducted a study to understand medieval musicologist research practices as part of a programme of empirical work investigating scholarship in transition across a variety of disciplines $[2,3,7,8,10$, $13]$.

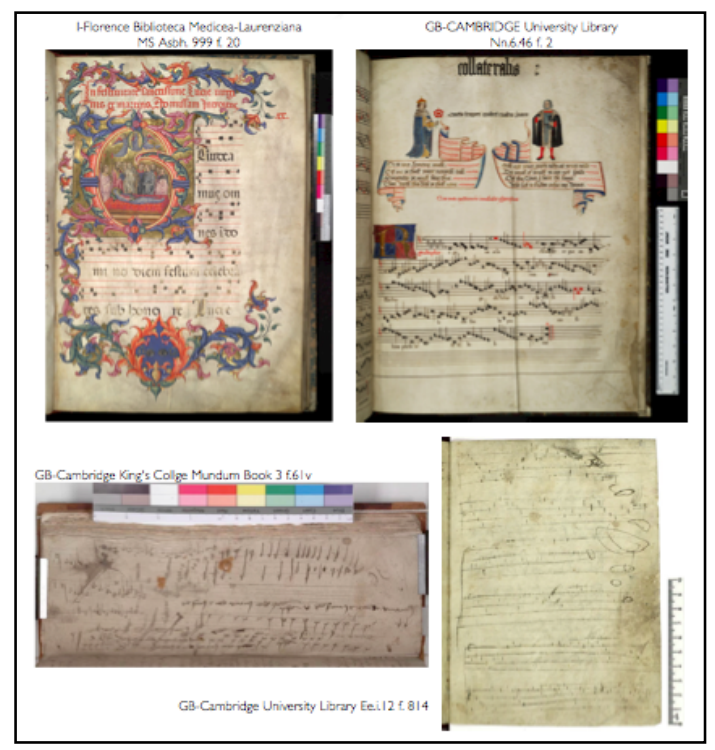

Figure 1. Variety of medieval music documents (the DIAMM Handbook).

With increased access to digital images of medieval documents new kinds of 'technical work' is being undertaken in order to draw out and reveal information that may not be accessible through the inspection of the physical documents alone.

\section{Digital images of medieval documents}

Digital image archives of medieval documents such as the Digital Image Archive of Medieval Music $\left(\right.$ DIAMM) ${ }^{1}$ and Teca Digitale Ricerca (TECA) ${ }^{2}$ were originally set-up to support the conservation of medieval music manuscripts. Such digitization initially ensured that their contents were still viewable in cases of their loss from natural degradation, theft or geopolitical difficulties to gaining access [5]. However, we find that, as in related disciplines, musicologists are increasingly drawing upon these archives to conduct research within virtual research environments (VREs).

Musicologists who use digital image archives such as DIAMM can inspect digital images of either a manuscript page or fragment (Fig. 2) which typically includes a manuscript item (1) a colour patch (2) and ruler (3). Both the colour patch and the ruler are physically placed alongside the manuscript in preparation for digital image capture. This is done to provide indications of its actual appearance and attempt to serve to assist in understanding aspects of physical documents as they are displayed in digital form.

$1 \mathrm{http}: / /$ www.diamm.ac.uk/index.html

2 http://teca.bmlonline.it/TecaRicerca/index_ENG.html 


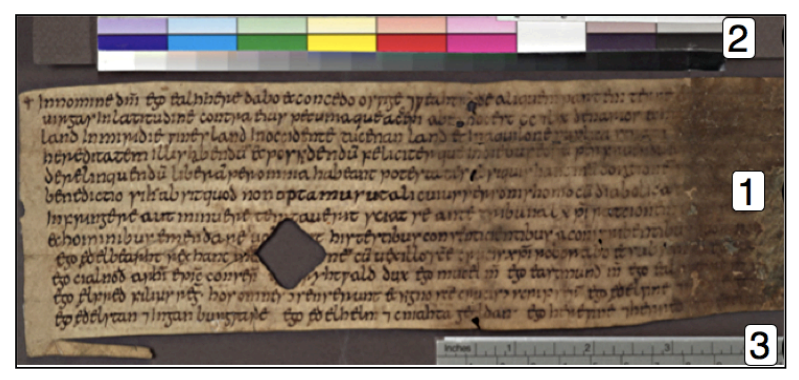

Figure 2. Manuscript fragment

Additionally, scholars may use music notation software such as Sibelius ${ }^{3}$ to transpose works into modern notation making it easier to analyse and compare manuscripts. For example, there may be visual differences between manuscripts such as a different orthography used for the same musical passage or differences in typography and layout. Only when unique individual pieces of music are transcribed into standard modern notation can the scholar see $a t-a$ glance if the musical arrangements are the same or different.

\section{Methodology}

For this case study we conducted in-person and telephone interviews with seven medieval music scholars distributed across three continents (Europe, North America and Australia). Additionally, we facilitated one focus group with five scholars to discuss the ways in which digital images are used in the analysis of medieval music documents. Finally, we conducted observational fieldwork sessions with medieval musicologists to acquire an understanding of how they use a variety of digital images as part of their routine work practice. This exploratory research study took place over a 12 month period from 2010-2011. The goal was to identify emerging requirements and inform software design by analyzing the kinds of substantive research practices scholars undertake using digital images, including how they use commercial offthe-shelf graphics software, how they interpret digital images as representations of physical documents, and their impact on research outputs.

The interview data was analysed to identify emerging patterns and themes [4] that the interviewees themselves discussed. Additionally, we draw upon ethnomethodology [11] and an analysis of conversation [16] in the study of video-recordings taken during observational fieldwork where a professional scholar and her student collaborate around digital images.

\footnotetext{
3 http://www.sibelius.com/home/index_flash.html
}

The interview data consisted of first-hand accounts, provided by the scholars, where they describe how research is conducted. These are useful, however the actually details of work and collaboration may not explicitly be discussed when using this technique. In order to triangulate our interview and focus group data we conducted observational fieldwork to reveal the 'seen-but-unnoticed' [12] aspects of the musicologists' work. We conducted two video-based observational fieldwork sessions in situ to understand their activities in detail as they worked with digital images. These observations have informed the identification of emerging requirements.

These data gathering activities have increased our understanding of the many ways that digital images are being used, as well as how they may be transforming research practices within medieval musicology. In the following sections, we present findings from our analysis and discuss how fieldwork techniques are utilised in the identification of requirements that may contribute to the design of more useful and usable systems.

\section{Digital images and their use in research}

In the following section, we present findings from our study that reveal how digital images are used in actual practice. We begin with a fragment taken from our video-based fieldwork observations where a professional scholar and her student are comparing two different documents of the same medieval chant 'Alleluia Dies Sanctificatus' (Alleluia for Christmas Day). What makes this 6th Century plainchant (multiple voices singing in unison) interesting to scholars is that this one musical piece has been found in two different 13th Century polyphonic (multiple voices singing different melodies simultaneously) documents. These two polyphonic musical pieces are made up of three voices: tenor, duplem, and triplem. One is known as the 'Cambridge' and the other as the 'Florence' manuscript. However, their names are no indication of their origin. In fact, both were written in Paris or northern France and are closely associated with Notre Dame Cathedral where the music is said to have originated.

To compare these two documents, the musicologists inspect digital images held in two separate digital image archives. The Cambridge document is located in The Digital Image Archive of Medieval Music (DIAMM) and the Florence document is accessible through the Teca Digitale Ricerca (TECA) website. Our observations of the interaction between scholar and student provided us with an opportunity to better understand how they use digital 
images of medieval documents as part of their routine research practice.

Because there are two versions of the same musical piece, the musicologists want to determine whether they are identical or whether there are any differences between them. These comparisons are important for reconstructing a piece of music as it would have been performed in that period. In addition to viewing the digital images of both documents they also transcribe them into standard modern notation so that they have a single standardised representation of the two uniquely written and formatted styles. Both of these practices assist in the identification of whether or not there is a pattern to any differences and what such a pattern may suggest. For instance, if the chant has been deliberately recomposed in a new way, or if it suggests some faulty process in reconstructing musical transmission, or that the scribe decided to creatively alter or extend a piece.

\subsection{Codicology: analysing the materiality of documents}

In the fragment below (Fig. 3) the professional scholar (left) and her student (right) begin their investigation with a consideration of the Cambridge document's physical properties. The student begins by asking a question about a mark on the page and considers whether it is a musical note or some other artifact such as damage. The scholar moves closer to the digital image to inspect it. They use the magnification/zoom feature to get a detailed look at the area and upon closer inspection the scholar indicates that it's actually an element of the document's decoration.

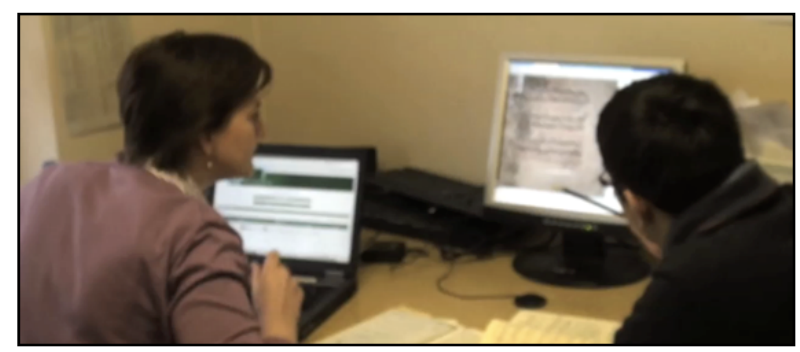

Figure 3. Investigating digital images of documents

Student: That's just a - it's not a note

Scholar: I think it's part of the decoration isn't it - I mean the colours - it would have been really vivid wouldn't they - blues and greens, yellows (and things)

Student: It's quite deteriorated

Scholar: I'm guessing this is a sort of slice in the - through the parchment isn't it?

Student: Yea
Scholar: It's showing white there

Student: Goodness only knows how it got there

Scholar: These are binding fragments they've been manhandled into the binding of another book and presumably a binder's knife has sliced through the pages. It's lucky in a way it's only sliced through the parchment

Here, the musicologists begin their inspection with the identification of a decorative element that upon first glance could be mistaken for damage or a musical note. However, in using the zoom feature to get a closer look at the image, the scholars are able to examine the document's material features in greater detail. In this case, ambiguous elements are more easily discerned using the zoom feature thus allowing the scholars to distinguish features within the document more clearly.

The resolution of ambiguities using the zoom feature supports the scholars in an area of substantive research practice known as 'codicology'. Through this practice scholars provide an account of the document's unique features and characteristics and describe these physical properties in detail as part of their research outputs. Being able to distinguish between what might be musical notes, decorative elements or damage using digital images suggests ways in which the researchers attempt to re-invoke the materiality of physical documents.

Although, the ability to zoom into areas within a document is a traditional practice when using a magnifying lens to inspect physical documents, it has been modified when inspecting digital images through digital magnification. In fact, scholars have commented that the high resolution of digital images actually makes it easier to distinguish areas within a document. Additionally, new codicological practices have emerged through the use of digital image manipulation and restoration software as one scholar we interviewed told us:

The traditional ways of detecting erasures is actually getting in there and consulting the manuscript. Now that is increasingly becoming more difficult ... it was very useful to actually have the color images to work with because something the computer technology allows someone to detect are erasures through the manipulation of the image gamma. That's the image gamma or the images levels, one can actually bring out what would normally be invisible, literally invisible on the page, to essentially a very clear indication that there's an erasure there, (MM-04).

Here the scholar is referring to his discovery of a substantial erasure made by a scribe at a point that dramatically changed the meaning of the musical notation within a document. This allowed the scholar 
to form an entirely new reading of the scribe's activity and was instrumental in forming a new interpretation of the scribe's participation in the production, history and reception of the music itself.

The details of how to conduct digital image manipulation and restoration activities is shared amongst musicologists informally through ad hoc email or in-person tutorials, and also through the distribution of the DIAMM Digital Restoration Workbook [6]. The workbook is widely known and distributed within the community and provides technical tutorials for how to use off-the-shelf commercial software to "restore an image to readability" through the manipulation of a digital image's colour, brightness, contrast, levels and sharpness as well as the realignment of elements within digital images such as staves. The workbook provides step-by-step sequences to follow that vary in complexity allowing scholars to produce digitally restored images.

Related aspects of materiality that scholars investigate include the paper or parchment the music was written upon, the method of binding into books, ink pigments and areas of deterioration. Musicologists use a variety of techniques to invoke the materiality of physical objects through, for instance, the ruler within the digital image to determine the document's actual size. Additionally, they analyse the digital images to determine the thinness of the document's parchment (where the thinner the parchment, the more expensive and so determinations can be made that it was most likely commissioned by a wealthy benefactor or institution). This can be identified through the appearance of colours from one side of the page as they 'show through' on the other side and has been reported to be much more easy to identify using digital images than either facsimiles or microfiche largely due to their much higher resolution. In addition, musicologists assess a document's damage more closely by zooming into areas of the manuscript to inspect ambiguous features in order to distinguish what may be smudges, holes or decoration from musical notes (Fig. 3).

Currently, for comparison purposes the scholars juxtapose digital images from two different archives by placing two computer monitors side-by-side with one computer connected to the DIAMM and the other to the TECA archives.

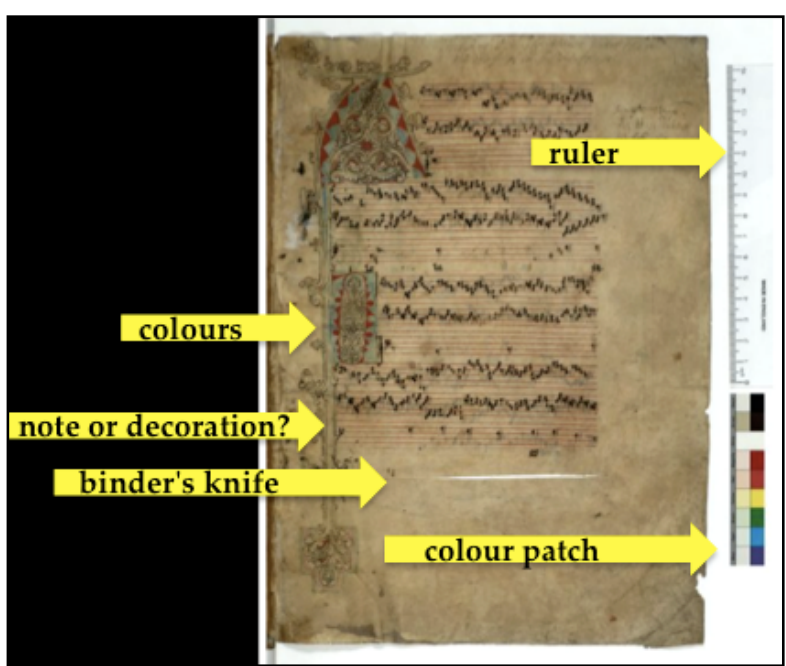

Figure 4. Analysing the materiality of documents

Working with digital images across separate archives may actually constrain their ability to compare and manipulate digital images because a) each has its own workspace tools and b) the images differ in quality. Both may raise challenges for digital medieval music archives in the development of minimum standards for digital image capture and for the availability of complementary tools for analysis.

\subsection{Paleography and Mise-en-page: inspecting the content and layout of documents}

In the previous section we discussed how digital images support research practices concerned with the materiality of documents. In this section we discuss the ways in which digital images support practices associated with the analysis of content found within documents, a practice known as 'paleography'. In the following fragment (Fig.5) the musicologists are comparing two $13^{\text {th }}$ Century manuscripts to determine which one is more faithful to the original $6^{\text {th }}$ Century plainchant source. As they compare the two documents the experienced scholar notices a difference between them in one line at the space in-between the clef (a symbol placed at the beginning of a staff indicating the pitch for the notes on that line) and the first note. In this case, there is a 'funny line' just after the clef in the Cambridge copy that does not appear in the Florence document and so this difference needs to be reconciled. 


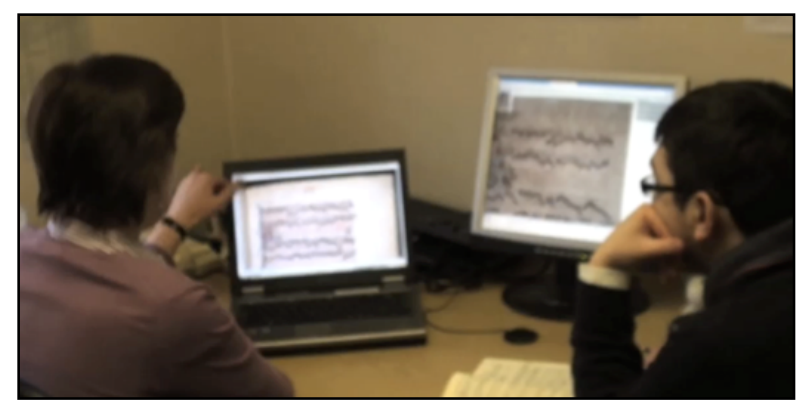

Figure 5. Deciphering the content of documents

Scholar: Well, our first question was that funny line at the beginning of that part - it's just not there in the Florence version of the piece is it?

\section{Student: No}

Scholar: So umm, until we can prove otherwise we assume it's just a mistake

\section{Student: OK}

Scholar: Something else as having significance to the Cambridge copy

Here, the scholar identifies the mark as a mistake in the Cambridge (top image) rather than in the Florence (bottom image) document (Fig.6).

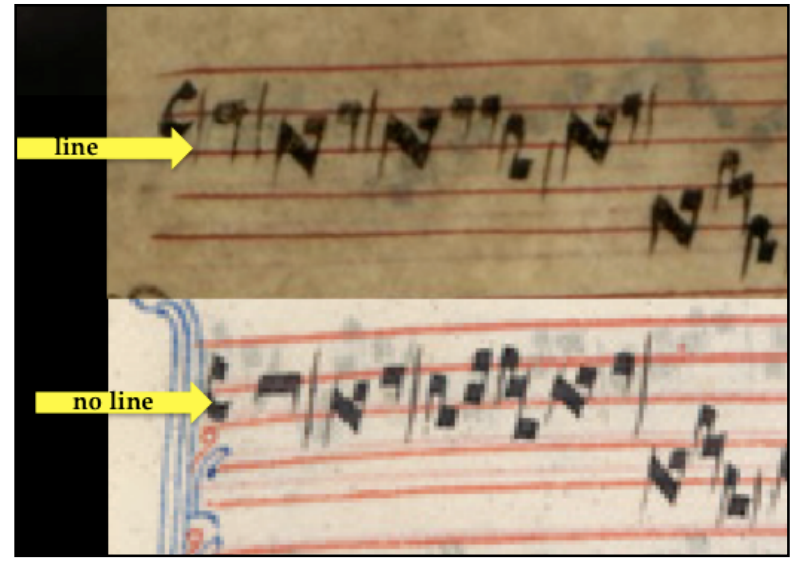

Figure 6. Analysing the content of documents

This analysis is made because in the notation for the second voice (just below the vocal part under consideration) in the Cambridge document (Fig. 7) there is no line after the clef. It is worth mentioning again that this is a polyphonic musical piece made up of three voices: tenor, duplem, and triplem. In this case, the line (interpreted as a rest or pause) at the top line (tenor) would put the duplem and triplem out of sync meaning the voice on the first line would start slightly after the voice on the second and third lines.

Here, we see how paleographic practices associated with the deciphering and comparison between documents is actually conducted using digital images.
The purpose of their analysis is to understand and compare both melodic and rhythmic differences allowing the scholars to contextualise and re-formulate the meanings of notational details within each of them.

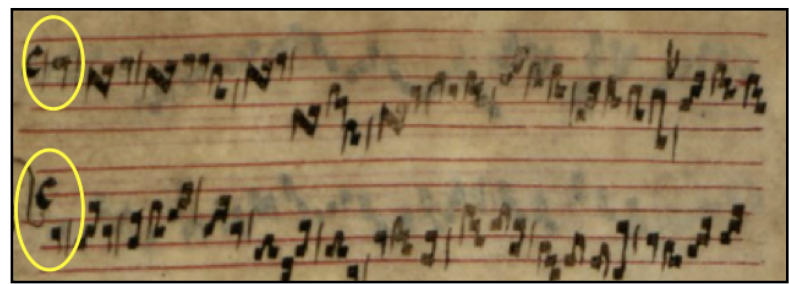

Figure 7. Cambridge document tenor and duplem

In addition to this, scholars examine the visual aesthetics of a document, known as 'mise-en-page', which involves the analysis of its typography, page layout, fonts, and illustrations. Research outputs from this include developing ontologies of layout features in order to understand their effects on the reading and performance of music, as well as to understand differences across scribes, regions and timeframes within the medieval period.

Such immediate access to digital images from the desktop makes it possible for scholars to assemble and compare documents archived in various libraries and museums across the world, as one musicologist we interviewed told us:

Give me a week or so and I can give you an overview [of a research topic] ... you can search in all sorts of ways [and] on your screen you can actually put an image from a manuscript from Cyprus and an image from a manuscript from St. Petersburg, an image from a manuscript from St. Andrews side-by-side. That way you can see things, you can draw direct comparisons, which wasn't always possible [because it required] a lot of traveling. But it's now come within reach [at the desktop], (MM-03).

Before digital image archives, this type of activity would have required extensive travel and would have taken many months to complete in order to view either the original document or microfiche versions of it. This new type of digital assembly work creates opportunities for quicker research outputs but may also present challenges for the ways in which systems are designed to support such work especially for piecing together fragments that may be from the same manuscript. According to a musicologist we interviewed this activity is similar to putting together pieces of a jigsaw puzzle where scholars rely upon feeling the edges of fragments to gauge which of them may actually fit together. 
Digital image archives may not only enable 'virtual research' they also allow scholars to conduct investigative 'excursions' that in the past would have required career-long commitments. In this way musicologists may engage in explorations into other branches of scholarly interest with no need to worry about its impact upon their long-term career paths, as a scholar we interviewed tells us:

It's not that I wouldn't have been able to do [this type of work] before, it's that it would have taken so much time, been so hard, and that I would have had to decide that's what my scholarship was going to be. Now, [I can conduct] four-day, five-day-long excursions that become five pages in the publication [instead of having to devote my entire career to these as would have been the case in the past], (MM-05).

These excursions may involve trying to understand the cultural context in which the manuscript was written through an analysis of historical documents such as receipts of sale and payment slips. In this way scholars have the opportunity to branch out in unexpected ways and with the availability of digitised documents they are able to answer research questions at a greatly accelerated pace.

These details make up musicologists' scholarly activities with the results of their work presented in medieval musicology journals, conferences and outreach lectures to the general public. Through interviews, a focus group and observational fieldwork we are able to understand, in detail, both the analytic and methodological concerns of musicologists and the ways in which these contribute to substantive research practice such as distinguishing marks within a digital image, conducting comparisons between manuscripts, and examining its decorative features and page layout. These fieldwork activities have a direct impact in our ability to identify emerging requirements especially as we develop an understanding of the ways in which scholars are interested in both the condition and content of medieval documents and conduct activities such as assembly work, digital image manipulation and image comparison. Though such scholarly activities are currently supported we can suggest more novel design interactions through our newly acquired understanding of how these activities are performed when using e-Research systems to conduct real-world research.

\section{Conclusion and future work}

We now turn to a consideration of how our analysis might be used to reflect upon and inform the requirements for systems particularly in support of three key substantive research practices conducted within medieval musicology; codicology, paleography, and mise-en-page. It should be noted that these practices are not conducted in a linear fashion; rather, a scholar may consider all simultaneously in their analysis of a document. Nonetheless, it is useful to discuss each as discreet elements especially when working towards the identification of requirements to support those practices.

\subsection{Supporting the analysis of a document's materiality}

First, codicological practices focus on the analysis of a document's physical properties, such as its decorative elements, size, binding, and areas where it is deteriorated. Currently, digital image archives offer a zoom feature, a ruler and a colour patch to assist scholars in those activities. However, it is clear that scholars would also benefit from detailed geometric and texture mapping of physical documents. Therefore, 3D scans could be utilized to allow scholars to examine medieval documents in far greater detail than is possible with digital images alone. 3D scans would make it possible to investigate a document's contours and textural qualities by rotating and zooming in to mesh models. They may also be useful for the assembly of fragments into a single document where edges could be fitted together using 3D digital restoration tools. In addition, the following requirements have emerged from the study.

Other requirements related to the analysis of a document's materiality focus on the identification of erasures as well as the digital restoration of damaged areas within a manuscript. Post-processing techniques are currently available only through the use of standalone software. However, digital images are not always available for download onto the desktop and so scholars have expressed an interest in having image manipulation features available directly within the online workspace. Such tools could enhance the examination of a manuscript's physical properties through the availability of features such as adjustment of gamma levels, brightness and contrast.

Additionally, because digital images are assembled together from geographically distributed archives and placed in juxtaposition to each other to conduct comparisons between documents. Seamless cross access to databases with a variety of manuscripts from around the world would enable easier manuscript fragment comparison so that scholars may understand the relationships between different source materials. In this case, workspace tools for the assembly and juxtaposition of fragments and manuscripts could better support these activities. 


\subsection{Supporting the analysis of a document's content}

Second, scholars conduct activities associated with the analysis of a document's content. These include mise-en-page where they carry out an inspection of a document's typography, character shape, illustrations, decorative features, and overall visual layout. In this case, further requirements may include a feature that would allow scholars to delineate areas of damage, decorative features, musical notes, and other features. This might include an annotation and tagging tool that could be used for research as well as teaching and learning purposes enabling scholars to identify, differentiate and mark the various elements that make up a document. However, it is important also to consider the ways in which annotation might obscure the image and to develop solutions to work around such a constraint.

\subsection{Making connections with and between associated materials and search}

Third, paleographic practices focus on the content of documents where scholars are interested in deciphering and reading words and musical notes as well as trying to identify the scribes who wrote them. We found that scholars required two computer monitors to compare documents archived in two different digital image archives. However, since eResearch is intended to support seamless global collaboration, we might think of ways to link data and images between archives making it possible to crosssearch and to compare images between the two (and possibly others) in a single virtual workspace. Additionally, we may consider the use of interactive tabletops and touch screens [15] to support embodied activity and interaction [14]. This might be especially interesting when we consider that digital documents could be placed flat on a table as they would be when inspecting physical documents.

Other requirements that have emerged include the need for specific types of search techniques. Scholars search the content of documents currently through manual visual detection. However, Optical Music Recognition (OMR) technology could be implemented to search through the individual notes within and across manuscripts allowing for detailed information about a document's rhythmic and melodic properties to be discovered. For instance, scholars would be able to run searches such as "show all musical pieces that are in triple time, that begin on $\mathrm{C}$, that use red notes in the middle". Musicologists have expressed interest in implementing such technology because it could result in more complex advance searching and comparison across diverse data sources. Novel technologies such as OMR may significantly speed up and make the process of identifying musical notes and comparing across manuscripts significantly easier and quicker. However, they may also present challenges to the identification of anomalies in scribal writing [7] which don't conform to standard styles, thus rendering invisible novel features that may be of interest within documents.

Other requirements identified include the ability to discover connections between people who may in someway be related to the manuscripts such as instrument makers, concert hall clerks, benefactors and others who had contact with the music at that time. Here, a search tool for linking together associated materials to corresponding digital image archive databases could be developed. Gaining insight about the association of manuscripts with other cultural artefacts such as receipts of sale, correspondence letters, and payment slips enable thick descriptions to be developed that outline the historical context in which a manuscript might have been written. Additionally, learning and teaching material could be developed so that academics might use these complementary resources as a teaching tool.

\subsection{Challenges to digital image use within research contexts}

In addition to identifying requirements scholars also discussed two key challenges in the use of digital images. First, there are challenges for sharing related to copyright issues. Each library or museum that owns music manuscripts requires assurances that they would keep the rights to any digital images produced from their collections. In some cases the manuscript holders have allowed digital images to be taken but they do not allow permission for the images to be made available on the Web. In such cases, the researcher must acquire permission from the manuscript holder to access the digital image. These are usually held in what are called 'dark archives' (images hidden from public view). Additionally, some digital archives create functionality that prevents them from saving online images on to the user's desktop, thus protecting the images from being copied.

Second, there is some pressure to continue conducting research in a traditional manner. In medieval musicology the tradition of working with actual documents is strong and some in the discipline may question the capacity of digital images to deliver meaningful knowledge about these objects. In this case, we need to understand in greater detail what it is the scholars do with real documents through fieldwork studies of traditional practices. In this way, we could 
begin to map out the ways in which digital images both support and constrain those practices. However, even with these challenges, the scholars we talked with emphasised the importance of digital images to scholarly research.

\subsection{Future work}

This case study has shown how digital images of medieval documents are used both to conduct activities and reveal details which are not accessible through the inspection of physical documents alone. We have also discussed how digital images have enabled scholars to ask new research questions particularly in relation to uncovering erasures and making comparisons between documents distributed across the globe. We find that contrary to common notions of user resistance that these scholars are very positive about the potential impact new technologies might have on their research practice.

Additionally, digital images provide a focus for collaborative work that may be both collocated and distributed, a key goal of the e-Research programme. Previously, manuscripts might have been deciphered by a lone scholar over a period of time and findings only published when the whole research process had been completed. However, e-Research environments that link to archives such as those discussed in this paper provide the potential not only for emerging interpretations of a medieval document to be discussed by groups of colleagues, but may also allow new interpretations to be published much more quickly. This may accelerate the research process by providing colleagues with the ability to discuss and comment on each other's work and share expertise.

In previous papers [7, 8, 9, 15] we have drawn upon detailed analyses of technological interventions to discuss requirements for designing virtual research environments so that scholars from different disciplines may produce collaborative interpretations. In particular, we find emerging themes across case studies where common features and functionality could be useful. These include image restoration and manipulation, the juxtaposition of various documents side-by-side, the annotation and tagging of areas within an image, associating images with other historical resources and finally, the ability to search across documents and archives. Across case studies, support for developing an understanding of the materiality of physical objects is a key requirement. This includes recreating and enhancing depth of field, colour, tactile qualities, weight, shape and size, as well as its content. Digital images of physical objects constrain the senses and the scholars' ability to understand a cultural object's materiality. This constraint provides us with an opportunity to work towards the development of more novel approaches to the analysis of physical objects when they are displayed through digital images.

Finally, workplace studies complement traditional requirements elicitation techniques such as interviews, surveys and focus groups. Observational fieldwork can be used to triangulate interview and focus group data and reveal the details of actual work practice as it takes place in situ. Additionally, workplace studies may address methodological issues in the identification of requirements for e-Research systems. These include taking into account support for global collaboration using online workspaces. We suggest that an approach we term 'thin slice deep cut' [9] may be used to address this challenge where relatively short-term periods of data collection are conducted, often relying upon gathering small fragments of key substantive research activities which are then subject to detailed analysis. Such activities could run parallel to prototype development so that incremental iterations of a system may be evaluated by the researchers who would use them using quasi-naturalistic experiments.

However, challenges to our understandings of global collaboration remain. For instance, considerations of how to scale up the study of work practice, communication and collaboration across global networks whilst maintaining a commitment to developing a deep understanding of researchers' complex skills and practices are a key challenge. As we work towards the development of solutions to this and other challenges it remains certain that the substantive research practices of scholars, as they transition their activities into digital workspaces, must inform the design of more novel systems. This will ensure that new features and functionality are aligned to the relevant concerns and activities that inform scholarly research practice.

\section{Acknowledgements}

We would like to thank the medieval musicology scholars who took part in our interviews and fieldwork. Additionally, we thank the Research Information Network RIN P28, and EPSRC grant EP/P503876/1 and the ESRC Digital Social Research Programme ESRC RES-149-34-0001for making this research possible.

\section{References}

[1] Atkins, D. et al., Revolutionizing Science and Engineering Through Cyberinfrastructure: Report of the National Science Foundation Blue-Ribbon Advisory Panel on 
Cyberinfrastructure. National Science Foundation Report, 2003, http://www.nsf.gov/od/oci/reports/toc.jsp.

[2] Bos, N., Zimmerman, A., Olson, J., Yew, J., Yerkie, J., Dahl, E., Olson, G., "From shared databases to communities of practice: A taxonomy of collaboratories", Journal of Computer-Mediated Communication, 12(2), http://jcmc.indiana.edu/vol12/issue2/bos.html, article 16.

[3] Bulger, M., Meyer, E.T., de la Flor, G., Terras, M., Wyatt, S., Jirotka, M., Eccles, K. and McCarthy Madsen, C., "Reinventing Research? Information Practices in the Humanities", The Research Information Network, Technical Report. 2011.

http://www.rin.ac.uk/system/files/attachments/Humanities_C ase_Studies_for_screen_2_0.pdf

[4] Corbin, J. and Strauss, A., "Grounded Theory Research: Procedures, Canons, and Evaluative Criteria", Qualitative Sociology, 13(1), 1990, pp. 3-21.

[5] Craig-Mcfeely, J., "Digital Image Archive of Medieval Music: The evolution of a digital resource", Digital Medievalist, 3, 2008,

http://www.digitalmedievalist.org/journal/3/mcfeely.

[6] de la Flor, G., Jirotka, M., and Meyer, E.T., "Accessing Medieval Music: from material codex to digital specimen", In Conference of Visualisation in the age of computerisation, Saïd Business School, University of Oxford, 2011.

[7] de la Flor, G., Luff, P., Jirotka, M., Pybus, J., Kirkham, R., and Carusi, A., "The Case of the Disappearing Ox: Seeing Through Digital Images to an Analysis of Ancient Texts", In Procs. 28th ACM Conference on Human Factors in Computing Systems, CHI 2010, Atlanta GA, 2010, pp. 473-482.

[8] de la Flor, G., Ojaghi, M., Martínez, I., Jirotka, M., Williams, M., Blakeborough, T., "Reconfiguring practice: the interdependence of experimental procedure and computing infrastructure in distributed earthquake engineering", Philosophical Transactions of the Royal Society, A, 2010, pp. 4073-4088.
[9] de la Flor, G., Jirotka, M., Luff, P., Pybus, J., Kirkham, R., "Transforming scholarly practice: embedding technological interventions to support the collaborative analysis of ancient texts", Journal of Computer Supported Cooperative Work, 19(3/4), 2010, pp. 309-334.

[10] Fraser, M., Hindmarsh, J., Best, K., Heath, C., Biegel, G., Greenhalgh, C. \& Reeves, S., "Remote Collaboration over Video Data: Towards Real-Time e-Social Science", Journal of Computer Supported Cooperative Work, Special Issue on Collaboration in e-Research, 15(4), 2006, pp. 257279.

[11] Garfinkel, H. Studies in ethnomethodology. PrenticeHall, Englewood Cliffs, NJ, USA, 1967.

[12] Hey, T., Trefethen, A., "e-Science and its Implications", Philosophical Transactions of the Royal Society A, 361, 2003, pp. 1809-1825.

[13] Jirotka, M., Procter, R., Hartswood, M., Slack, R., Simpson, A., Coopmans, C., Hinds, C. and Voss, A., "Requirements for Collaboration and Trust in Healthcare Innovation: The eDiaMoND Case Study", Journal of Computer Supported Cooperative Work, 14(3), 2005, pp. 369-398.

[14] Luff, P., Jirotka, M., Yamashita, N., Kuzuoka, H., de la Flor, G., Heath, C., "Interactional Validity: Assessing technologies to support embodied activities", In Workshop on Embodied Interaction: Theory and Practice, 2011, In HCI, 29th ACM Conference on Human Factors in Computing Systems, CHI'11.

[15] Nacenta, M.A., Pinelle,D., Stuckel,D., Gutwin,C., "The Effects of Interaction Technique on Coordination in Tabletop Groupware", In Proc. Graphics Interface Conference '07, 2007, ACM, New York, NY, pp. 191-198.

[16] Sacks, H. Lectures in Conversation: Volumes I and II. Blackwell, Oxford UK, 1992. 